\title{
Quantitative evaluation of personal protective ensembles relative to heat strain
}

\author{
Xiaojiang $\mathrm{Xu}^{*}$, Julio Gonzalez \\ From 15th International Conference on Environmental Ergonomics (ICEE XV) \\ Portsmouth, UK. 28 June - 3 July 2015
}

\section{Introduction}

Personal protective equipment (PPE) exacerbates heat strain experienced by users through: (a) increases in thermal $\left(R_{t}\right)$ and evaporative $\left(R_{e t}\right)$ resistances; and $(b)$ increases in metabolic rate $(\dot{\mathrm{M}})$ during physical activity driven in large part by ensemble weight. This study aimed to quantify the effects of PPE $R_{t} \& R_{e t}$ and ensemble weight on heat strain during walking.

\section{Methods}

Stepwise thermal manikin (TM) testing and modeling were used to analyse a three-layer PPE ensemble (weight $37.4 \mathrm{~kg}$ ). Layers: uniform (A); body armour and combat load (B); chemical protective clothing (C). The PPE was tested on a TM to measure $R_{t} \& R_{e t}$, starting with layer $A$ and then adding an additional layer in each step. $\dot{M}$ during walking at $1.22 \mathrm{~m} . \mathrm{s}^{-1}$, adjusted $\left(\dot{\mathrm{M}}_{\text {adj }}\right)$ for the layer weight, were 300,404 and $428 \mathrm{~W}$ for configurations with $\mathrm{A}, \mathrm{A}+\mathrm{B}$ and $\mathrm{A}+\mathrm{B}+\mathrm{C}$, respectively. A human thermoregulatory model was used to predict endurance time (ET, min) for each configuration at a fixed $\dot{M}\left(\dot{M}_{\text {fix }}\right)$ of $300 \mathrm{~W}$ and at its $\dot{\mathrm{M}}_{\text {adj }}$ ET was defined as time needed for the core temperature to rise to $39^{\circ} \mathrm{C}$.

\section{Results}

The left figure indicates the fractional contribution of each layer to $R_{t} \& R_{e t}$ of the whole system $(A+B+C)$. The right figure is the predicted ET, showing influences of $\mathrm{B}$ or $\mathrm{B}+\mathrm{C}$ in comparison with $\mathrm{A}$. The difference between $A$ and $A+B-\dot{M}_{\text {fix }}$ indicates ET reduction due to $R_{t} \& R_{e t}$ with added $B$, and the difference between $A+B-$ $\dot{\mathrm{M}}_{\mathrm{fix}}$ and $\mathrm{A}+\mathrm{B}-\dot{\mathrm{M}}_{\mathrm{adj}}$ indicates $\mathrm{ET}$ reduction due to the

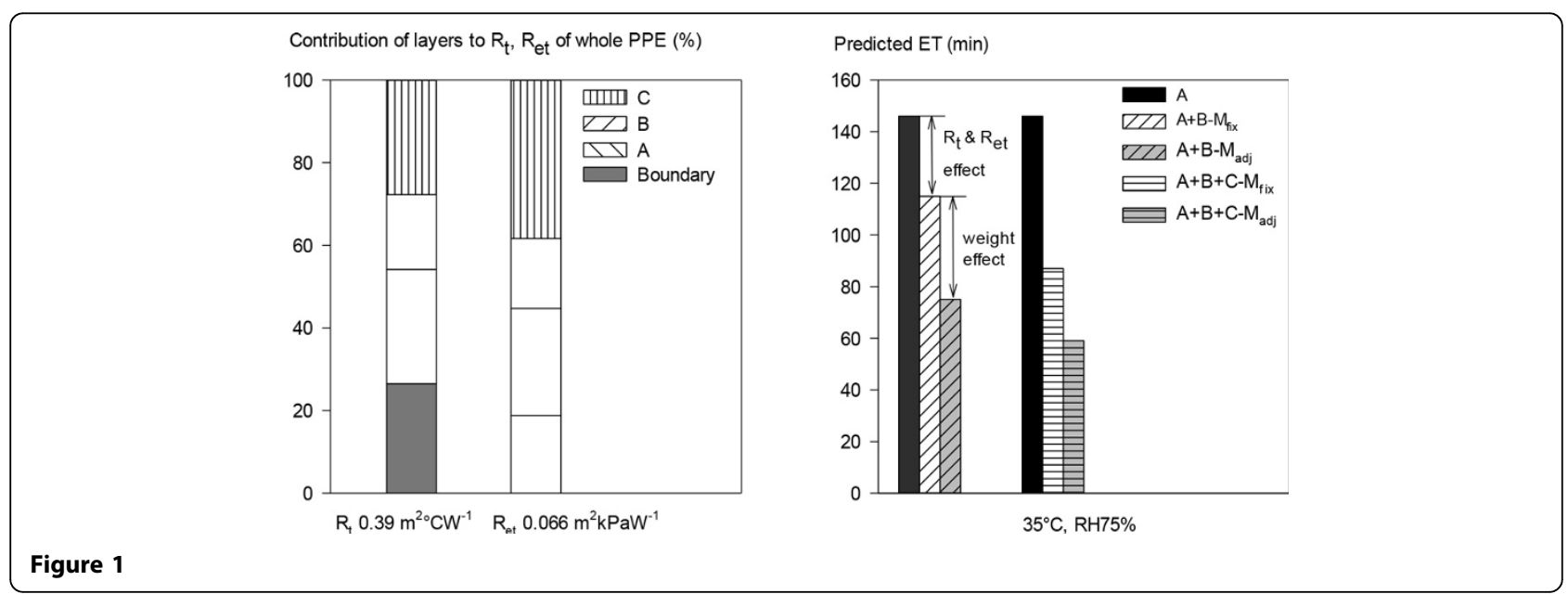

\footnotetext{
* Correspondence: xiaojiang.xu.civ@mail.mil

US Army Research Institute of Environmental Medicine Biophysics/ Biomedical Modeling Division, Natick, MA 01760, USA
}

(c) 2015 Xu and Gonzalez; This is an Open Access article distributed under the terms of the Creative Commons Attribution License (http://creativecommons.org/licenses/by/4.0), which permits unrestricted use, distribution, and reproduction in any medium, provided the original work is properly cited. The Creative Commons Public Domain Dedication waiver (http://creativecommons.org/ publicdomain/zero/1.0/) applies to the data made available in this article, unless otherwise stated. 
weight of B. Thus compared with ET for A of $146 \mathrm{~min}$, the $R_{t} \& R_{e t}$ of $B$ reduce ET by 31 min while the added weight reduces ET by 40 min further. Similarly, the increased $R_{t} \& R_{\text {et }}$ of $B+C$ reduce ET by 59 min, while the added weight reduces ET by $28 \mathrm{~min}$.

\section{Discussion}

This study (a) reveals the fractional contributions of PPE resistances by layer, (b) demonstrates the effects of PPE weight on ET and quantifies ET reduction due to increases in $\dot{M}$ associated with PPE weights, and (c) isolate the contributions of two different PPE properties, $R_{t} \& R_{e t}$ and ensemble weight, to predicted heat strain. Impacts of each PPE layer on ET can be quantified by this approach.

\section{Conclusion}

This study provides a new systematic approach to understanding more the aetiology of heat strain, and to designing PPE to maximise user protection while minimizing heat strain.

\section{Acknowledgements}

The views expressed in this abstract are those of the authors and do not reflect the official policy of the Department of Army, Department of

Defense, or the U.S. Government.

Published: 14 September 2015

doi:10.1186/2046-7648-4-S1-A133

Cite this article as: Xu and Gonzalez: Quantitative evaluation of personal protective ensembles relative to heat strain. Extreme Physiology \&

Medicine 2015 4(Suppl 1):A133.
Submit your next manuscript to BioMed Central and take full advantage of:

- Convenient online submission

- Thorough peer review

- No space constraints or color figure charges

- Immediate publication on acceptance

- Inclusion in PubMed, CAS, Scopus and Google Scholar

- Research which is freely available for redistribution

Submit your manuscript at www.biomedcentral.com/submit 